\title{
CAUSES OF HOSPITALIZATION AMONG CHILDREN AGES ZERO TO NINE YEARS OLD IN THE CITY OF SÃO PAULO, BRAZIL
}

\author{
Ana Paula Scoleze Ferrer, Ana Cecília Silveira Lins Sucupira, Sandra Josefina \\ Ferraz Ellero Grisi
}

doi: 10.1590/S1807-59322010000100007

Ferrer APS, Sucupira ACSL, Grisi SJFE. Causes of hospitalization among children ages zero to nine years old in the city of São Paulo, Brazil. Clinics. 2010;65(1):35-44.

INTRODUCTION: The profile of child morbidity is an important parameter for defining and altering health policies. Studies about infant mortality are more numerous than those on morbidity, especially related to hospital admissions. The objective of this study is to describe the causes of admission in the public health system for children from zero to nine years of age in the city of São Paulo during the years 2002 to 2006 and compare these results to those from the national data.

METHOD: Through a cross-sectional study, data were obtained from the Hospital Information System, which is available in the Information System of the Unified Health System - DATASUS.

RESULTS: Within the period, $16 \%$ of the total admissions corresponded to children from zero to nine years of age, with most of the children being younger than one year of age. In the city of São Paulo, the admission coefficient increased 11\%, and in Brazil, it decreased $14 \%$. Respiratory diseases were the main causes of hospitalization. In São Paulo, the second most frequent causes of admission were diseases that originated during the perinatal period (15.9\%), and in Brazil, the second most frequent cause of admission was infectious-parasitic diseases (21.7\%). Admissions for perinatal diseases increased 32\% in São Paulo and 6\% in Brazil. While hospitalizations for diarrhea decreased in Brazil, an increase was recorded in the city of São Paulo for children under five years old. CONCLUSIONS: The findings of this study show a paradoxical increase in the number of hospitalizations during an expansion of primary attention, indicating that the rise was not associated with a significant improvement in the quality of service.

KEYWORDS: Hospitalization; Morbidity; Child health services; Child care; Health policy.=

\section{INTRODUCTION}

Epidemiology is not just a science; it is also an instrument that allows health appropriate policies to be developed to fit the characteristics of a certain population, of a certain place, in a certain period. The field of epidemiology is based on studies of particular health situations, specifically the distribution and frequency of diseases and complications. These results then provide information that helps create strategies and specific actions directed to the reality of the

Department of Pediatrics, Faculdade de Medicina da Universidade de São Paulo, São Paulo/SP, Brazil.

Email: ana.ferrer@icr.usp.br

Tel: 55113069.8500

Received for publication on July 02, 2009

Accepted for publication on October 19, 2009 studied population in addition to evaluating the impact of those actions on the control of diseases. ${ }^{1}$

A population's morbimortality profile is the result of the interaction of multiple interdependent factors and is considered "a relatively sensitive indicator of the life conditions and of the model of development of a population". ${ }^{2}$ The knowledge of this profile, through studies of morbidity and mortality, allows us to identify the health needs of a population and organize health services in response to the studied group. ${ }^{3}$

Hospital morbidity, which represents the most serious group of diseases and people who have access to the hospital, has special importance when it comes to representing the portion of health system that absorbs the greatest amount of resources. Moreover, some authors 
consider the information about rates and causes of hospitalization an important indicator of the quality of the attendance offered and an indirect indicator of how outpatient consults are resolute. ${ }^{4}$

Social and economic changes have provoked a phenomenon known as epidemiologic transition; through this transition, there has been an expressive reduction in the prevalence of infectious - contagious diseases, an improvement in the nutritional conditional, and an increase of the prevalence of chronic-degenerative and externally cause diseases. Those transformations, associated with changes in the demographic pattern, caused alterations in the morbimortality profile of the population. Therefore, in Brazil, and particularly in the city of São Paulo, an expressive reduction in infant mortality rates was observed, increasing the importance of studies about childhood morbidity, which can be more significant for decisions in public health. Those types of studies, however, are rare in our environment.

The purpose of the present study was to describe the causes of hospitalization, in the public health system, of children from zero to nine years of age in the city of São Paulo. These results were then compared to national data over a period of five years, 2002 to 2006, when important local changes in health policies occurred.

\section{METHOD}

This work is a descriptive and analytic cross-sectional study about hospitalization of children from zero to nine years of age in the São Paulo public health system, during a five-year period. The admissions that occurred from January 2002 to December 2006 were appraised. The study began in 2002 because the city of São Paulo joined the Unified Health System, Sistema Único de Saúde (SUS), in 2001. The study concluded in 2006 because it appeared as though all necessary information was contained in the updated and complete database, considering a latency between the occurrence of the hospitalization and its inclusion in the information system.

Information was obtained from the database contained in the Hospital Information System of SUS (SIH-SUS), available at http://w3.datasus.gov.br/datasus/datasus.php, with the following options selected: Information on Health, Epidemiological and Morbidity, Hospital Morbidity, General by place of hospitalization, from 1984 to 2007. The tabulation program data (system TABNET of DATASUS), Microsoft Office Excel 97 was used. All of the data were compiled according to the place of hospitalization for the city of São Paulo and for Brazil.

The SIH-SUS is a database that originated from the
Authorizations of Hospital Admission (AIH), a form filled out in all hospital admissions subsidized by SUS because it is used for financial reimbursement at those hospitalizations. The SIH-SUS is an important tool for epidemiological surveillance, and it is useful for evaluating actions on health. ${ }^{5}$ The SIH-SUS presents, however, some problems concerning the reliability of the diagnosis and completion of the $\mathrm{AIH}^{6.6}$ The main advantages in using the SIH-SUS are as follows: the national coverage, the great volume of data available, easy access to the information, and the short interval of time between the occurrence of the event and registration in the system. ${ }^{7}$ Therefore, the use of the SIH-SUS has been validated as an important source of information related to morbidity, the quality of service and the use of the services, which allows for the evaluation and improvement of health care. ${ }^{7-9}$

To make the absolute number of internments to be relative to the appraised population allowing the comparison of different aged populations during all studied years and within different geographical areas, the coefficient of hospitalization (CI) for each 1,000 children was calculated according to the formula:

$\mathrm{Ci}=\frac{\text { Total number of admissions for a specific age group, year and place }}{\text { Corresponding population of the age group; year and place }} \times 1000$

Data about the population were obtained from the same electronic address, selecting "IDB - Indicators and basic data of Brazil," which originated from the Brazilian Institute of Geography and Statistics (IBGE - local acronym).

The research project was evaluated and approved by the Commission of Ethics for Analysis of Research Projects, CAPPesq of the Clinical Board of Directors of Hospital das Clínicas - School of Medicine of the University of São Paulo.

\section{RESULTS}

During the studied period, 451,303 hospitalizations of children ages zero to nine occurred in the city of São Paulo, which corresponds to $16 \%$ of the total number of hospitalizations in the city during the same period. In Brazil, out of the total admissions that occurred in the five years studied, 9,915,772 (17\%) were of children from zero to nine years of age. The percentage of hospitalizations in the age group studied relative to hospitalizations of other age ranges showed little variation during the five years studied, in both the municipal district and Brazil.

In the city of São Paulo, as in Brazil as a whole, the CI for children younger than one was considerably higher than the CIs for children of other ages, during the whole study period. In São Paulo, $74 \%$ of the hospitalizations corresponded to children 
younger than one, $16 \%$ corresponded to children between one and four years old, and $10 \%$ corresponded to children between five and nine years old. In Brazil, that distribution was 69\%, $22 \%$ and $9 \%$, respectively (Figure 1). With respect to gender, both in the city of São Paulo and in Brazil, males prevailed, with very similar values in both places (57\% and 56\%, respectively). The average hospital stay, considering all the hospitalizations that occurred during the studied period, was 7.3 days in the city of São Paulo and 6 days in Brazil. However, the average duration of hospitalization varied by age group. In São Paulo, the average time of hospitalization for children younger than one year was higher than any other age group, except for those older than 80 .

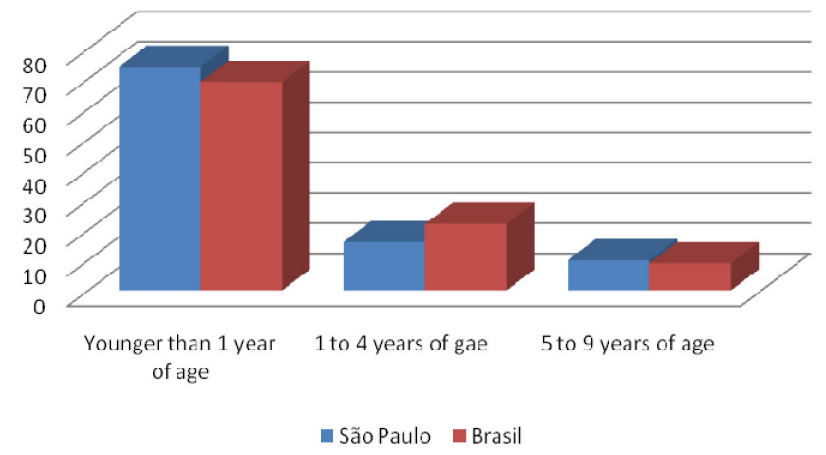

Figure 1- Distribution (\%) of the averages of the hospitalization coefficients by age group, in the city of São Paulo and Brazil during the five years studied, 2002 to 2006.

The CI for children from zero to nine years old in the city of São Paulo rose from 48.74 in 2002 to 54.07 in 2006. The opposite tendency was observed in the national data, where the CI for the same population decreased from 63.74 to 54.70 (Figure 2).

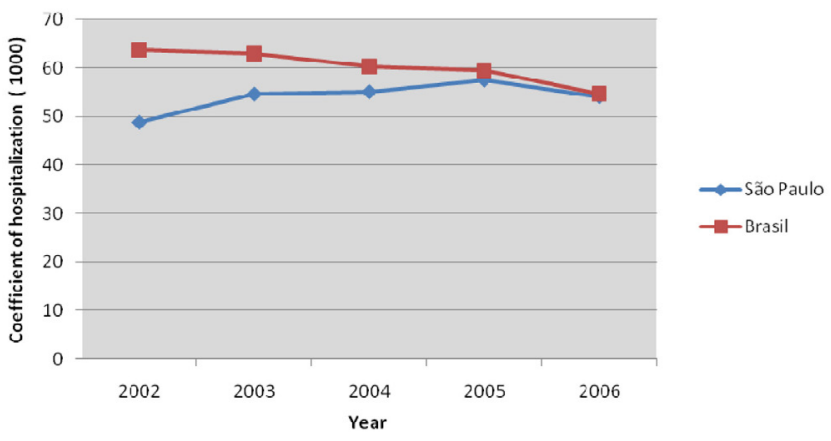

Figure 2 - Evolution of the hospitalization coefficient for children between zero and nine years of age in the district of São Paulo and Brazil, 2002 to 2006.

According to the CID-10 ( $2^{\text {nd }}$ edition $)$, during the period from 2002 to 2006, respiratory diseases were the main cause for hospitalization in the studied age group in the city of São Paulo and Brazil, accounting for $32.5 \%$ and $38.4 \%$ of the hospitalizations, respectively. Diseases that originated in the perinatal period were the second most frequent cause of hospitalization in the city (15.9\%) and third in Brazil $(10.1 \%)$. Diseases of the digestive system, including hernias, were the third cause of hospitalization in the city $(8 \%)$ and the fourth in Brazil. On the other hand, infectious and parasitic diseases, chapter of the CID-10 which includes acute diarrheas of infectious origin, are responsible for $7.9 \%$ of the hospitalizations in São Paulo, making it the fourth most common cause of hospitalization. However, in Brazil, infectious and parasitic diseases are the second highest reason of hospitalization, accounting for $21.7 \%$ of hospitalizations.

Table 1 - The top ten causes of hospitalization in children younger than one year of age, in the city of São Paulo, during the five years studied, 2002 to 2006

\begin{tabular}{|c|c|c|c|}
\hline Cause & $\begin{array}{c}\text { Number of } \\
\text { hospitalizations }\end{array}$ & $\begin{array}{c}\% \text { of the total } \\
\text { hospitalizations }\end{array}$ & $\begin{array}{c}\% \text { among the top ten } \\
\text { causes of hospitalization }\end{array}$ \\
\hline Pneumonia & 34,729 & 18.82 & 26.31 \\
\hline Other perinatal diseases ${ }^{1}$ & 22,826 & 12.37 & 17.29 \\
\hline Other perinatal respiratory diseases ${ }^{2}$ & 21,810 & 11.82 & 16.52 \\
\hline Fetal growth retardation, prematurity and low weight & 16,623 & 9.0 & 12.59 \\
\hline Acute bronchitis or bronchiolitis & 9,376 & 5.08 & 7.1 \\
\hline Asthma & 9,235 & 5.0 & 6.99 \\
\hline Other respiratory system diseases ${ }^{3}$ & 5,066 & 2.74 & 3.83 \\
\hline Infectious diarrhea and gastroenteritis & 4,961 & 2.68 & 3.75 \\
\hline Congenital malformations of the circulatory system & 4,231 & 2.29 & 3.2 \\
\hline Intrauterine hypoxia and asphyxia at birth & 3,140 & 1.7 & 2.37 \\
\hline
\end{tabular}

1- Includes conditions related to prolonged pregnancy and high birth weight, such as cardiovascular diseases, hemorrhagic diseases of the fetus and newborn, necrotizing enterocoliti, convulsions of the newborn, metabolic diseases and jaundice, among others.

2- Includes respiratory distress in the newborn, congenital pneumonia, neonatal aspiration syndrome, emphysema, pulmonary hemorrhage and chronic respiratory disease originating during the perinatal period.

3- Includes unspecified acute infections of the lower airway, lung and mediastinal abscesses, pleural effusion, pneumothorax and pulmonary edema, among other diseases that are less frequent in the pediatric practice. 
Among children younger than one year of age, the ten main causes were responsible for $71.5 \%$ of the admissions (Table 1). An analysis of the causes for hospitalization in the group younger than one year of age indicated that $49 \%$ were due to diseases originating in the perinatal period, $44 \%$ from respiratory diseases, $4 \%$ from acute diarrhea and $3 \%$ from congenital malformations of the circulatory system. Table 2 presents the development of CIs for the groups of causes during the five years studied. Perinatal diseases increased 32\% in the city of São Paulo and 6\% in Brazil; respiratory causes rose $30.8 \%$ in São Paulo and decreased $11 \%$ in Brazil. Acute diarrhea increased 54\% in São Paulo and was reduced $16 \%$ in Brazil, and hospitalizations for malformations of the circulatory system increased $1.9 \%$ in the district and $10 \%$ in other areas of Brazil among children younger than one year old.

In patients between one and four years of age, the ten main causes of hospitalization (Table 3), responsible for half of all of admissions can be grouped into six categories, including respiratory diseases $(63 \%)$, surgical causes $(18 \%)$, acute diarrhea (6\%), skin infections (5\%), malformations of the circulatory system (4\%) and other diseases of the nervous system (4\%). For the time period of 2002 to 2006, the evolution of CIs in each group of diseases is presented in Table 4. Hospitalizations for breathing diseases increased $26 \%$ in the city while decreasing $20.6 \%$ in Brazil. The CIs for surgical causes increased $17 \%$ in São Paulo and barely changed in Brazil, and the admissions for diarrhea increased two-fold in the city and $11 \%$ in the rest of the country.

The ten main causes for hospitalization among children from five to nine years of age (Table 5) are responsible for $44 \%$ of the admissions in that age range and can be grouped into the following major categories: respiratory diseases $(46 \%)$, surgical causes $(30 \%)$, lesions arising from external causes $(17 \%)$ and diseases of the nervous system (7\%). As shown in Table 6, the development of CIs reveals that all of the groups of causes had an increase in the number of city admissions during the five years studied.

Table 2- The hospitalization coefficients (per 1,000 children) for the major hospitalization causes in children younger than one year old - São Paulo and Brazil, 2002 to 2006

\begin{tabular}{lccccccc}
\hline Causes & Place & 2002 & 2003 & 2004 & 2005 & 2006 & Variation \\
\hline \multirow{2}{*}{ Perinatal } & São Paulo & 63.08 & 69.02 & 70.31 & 74.88 & 83.59 & $+32 \%$ \\
& Brazil & 48.30 & 46.92 & 47.72 & 51.03 & 51.20 & $+6 \%$ \\
\hline \multirow{2}{*}{ Respiratory } & São Paulo & 55.56 & 69.74 & 69.23 & 59.87 & 72.68 & $+30.8 \%$ \\
& Brazil & 69.32 & 72.42 & 68.01 & 61.37 & 61.52 & $-11.2 \%$ \\
\hline \multirow{2}{*}{ Acute diarrhea } & São Paulo & 4.36 & 4.86 & 5.84 & 6.03 & 6.72 & $+54 \%$ \\
& Brazil & 15.62 & 15.77 & 14.60 & 14.09 & 13.11 & $-16 \%$ \\
\hline \multirow{2}{*}{ Circulatory system malformations } & São Paulo & 4.75 & 4.93 & 4.88 & 4.26 & 4.84 & $+1.9 \%$ \\
& Brazil & 1.90 & 1.94 & 2.05 & 2.07 & 2.10 & $+10 \%$ \\
\hline
\end{tabular}

Table 3 - The top ten main causes of hospitalization in children between one to four years old in the distriet city of São Paulo, during the five years studied, 2002 to 2006.

\begin{tabular}{|c|c|c|c|}
\hline Cause & $\begin{array}{c}\text { Number of } \\
\text { hospitalizations }\end{array}$ & $\begin{array}{c}\% \text { of total } \\
\text { hospitalizations }\end{array}$ & $\begin{array}{c}\% \text { among the top ten } \\
\text { causes of hospitalizations }\end{array}$ \\
\hline Pneumonia & 32,568 & 20.96 & 40.46 \\
\hline Asthma & 14,893 & 9.58 & 18.50 \\
\hline Infectious diarrhea and gastroenteritis & 5,291 & 3.40 & 6.57 \\
\hline Other hernias ${ }^{1}$ & 5,057 & 3.25 & 6.28 \\
\hline Inguinal hernias & 4,958 & 3.19 & 6.16 \\
\hline Phimosis & 4,446 & 2.86 & 5.52 \\
\hline Infections of skin and subcutaneous tissues & 3,759 & 2.42 & 4.67 \\
\hline Chronic diseases of the tonsils and adenoids & 3,421 & 2.20 & 4.25 \\
\hline Congenital malformations of the circulatory system & 3,194 & 2.05 & 3.96 \\
\hline Other diseases of the nervous system ${ }^{2}$ & 2,899 & 1.86 & 3.60 \\
\hline
\end{tabular}

1- Includes umbilical hernia, diaphragmatic hernia, femoral hernia and abdominal hernia.

2- Includes spinal and muscular atrophies, extrapyramidal diseases, vascular cerebral syndromes, inflammatory polyneuropathy, myopathies, myasthenia gravis, hereditary and idiopathic neuropathies, hydrocephalia and diseases of the nervous system that are secondary to procedures, such as liquoric hypotension following punction. 
Table 4 - The hospitalization coefficients (per 1,000 children) for the major hospitalization causes in children one to four years old - São Paulo and Brazil, 2002 to 2006.

\begin{tabular}{|c|c|c|c|c|c|c|c|}
\hline Causes & Place & 2002 & 2003 & 2004 & 2005 & 2006 & Variation \\
\hline \multirow{2}{*}{ Respiratory } & São Paulo & 12.30 & 15.49 & 14.38 & 15.36 & 15.51 & $+26 \%$ \\
\hline & Brazil & 27.11 & 26.48 & 24.48 & 22.72 & 21.50 & $-20.6 \%$ \\
\hline \multirow{2}{*}{ Surgical } & São Paulo & 3.67 & 4.69 & 4.16 & 3.91 & 4.32 & $+17 \%$ \\
\hline & Brazil & 2.83 & 3.17 & 3.07 & 2.95 & 2.79 & $-1.4 \%$ \\
\hline \multirow{2}{*}{ Acute Diarrhea } & São Paulo & 0.95 & 1.41 & 1.53 & 1.75 & 1.94 & $+104 \%$ \\
\hline & Brazil & 5.46 & 5.91 & 5.67 & 5.97 & 6.07 & $+11 \%$ \\
\hline \multirow{2}{*}{$\begin{array}{l}\text { Malformations of the } \\
\text { circulatory system }\end{array}$} & São Paulo & 0.92 & 1.05 & 0.88 & 0.81 & 0.91 & $-1 \%$ \\
\hline & Brazil & 0.26 & 0.26 & 0.24 & 0.24 & 0.24 & $-8 \%$ \\
\hline \multirow{2}{*}{ Skin infections } & São Paulo & 0.79 & 0.90 & 1.01 & 1.49 & 1.19 & $+50.6 \%$ \\
\hline & Brazil & 0.33 & 0.42 & 0.45 & 0.53 & 0.52 & $+57.5 \%$ \\
\hline \multirow{2}{*}{ Nervous system diseases } & São Paulo & 0.61 & 0.71 & 0.79 & 0.98 & 1.06 & +73.7 \\
\hline & Brazil & 0.15 & 0.17 & 0.17 & 0.18 & 0.18 & $+20 \%$ \\
\hline
\end{tabular}

Table 5 - The top ten main causes of hospitalizations for in children between five and nine years old in the city of São Paulo during the five years studied, 2002 to 2006

\begin{tabular}{lccc}
\hline Cause & $\begin{array}{c}\text { Number of } \\
\text { hospitalizations }\end{array}$ & $\begin{array}{c}\text { \% of the total } \\
\text { hospitalizations }\end{array}$ & $\begin{array}{c}\text { \% among the top ten } \\
\text { causes of hospitalizations }\end{array}$ \\
\hline Pneumonia & 9,163 & 8.21 & 18.70 \\
Asthma & 7,020 & 6.29 & 14.32 \\
Chronic diseases of the tonsils and adenoids & 6,442 & 5.77 & 13.14 \\
Fracture of the limb bones & 5,798 & 5.20 & 11.83 \\
Inguinal hernia & 4,220 & 3.78 & 8.61 \\
Phimosis & 3,815 & 3.42 & 7.78 \\
Other diseases of the nervous system $^{1}$ & 3,637 & 3.26 & 7.42 \\
Other hernias $^{2}$ & 3,340 & 2.99 & 6.81 \\
Diseases of the appendix $_{\text {Cranial trauma }}$ & 3,204 & 2.82 & 6.53 \\
\hline
\end{tabular}

1- Includes spinal and muscular atrophies, extrapyramidal diseases, vascular cerebral syndromes, inflammatory polyneuropathy, myopathies, myasthenia gravis, hereditary and idiopathic neuropathies, hydrocephalia, and diseases of the nervous system that are secondary to procedures, such as liquoric hypotension following punction.

2- Includes umbilical hernia, diaphragmatic hernia, femoral hernia and abdominal hernia.

\section{DISCUSSION}

Although infant mortality rates are progressively declining, the number of children hospitalizations has not shown the same trend, particularly for some morbid conditions. The data regarding the most frequent conditions were analyzed; here, we try to discuss possible conditioning factors for these findings.

Modern epidemiology has been adopting the risk focus as a router for the primary attendance to health, and mothers and children are considered a very vulnerable group. Therefore, attention to maternal-infantile health has been prioritized in the public policies of attendance. ${ }^{10}$ The high percentages of children between zero and nine years old admitted to the hospital, $16 \%$ in São Paulo and $17 \%$ in
Brazil, reflect the vulnerability of that age group. The great predominance of hospitalizations during the first year of life and the longer average hospital stays at that age show that the immunological immaturity of those children and their anatomical characteristics put them at a higher risk of having a severe case of disease and getting sick in general. Besides, considering the growing importance of perinatal diseases as causes of hospitalization, it is natural that children younger than one year old are the most hospitalized group. Those data match the work of Castro et al (2002), ${ }^{11}$ who studied factors associated with hospitalizations in Brazil, using the 1998 National Research by Home Sampling (PNDA), described a $13 \%$ decrease in the chance of hospitalization for each one year increase in a child's age. The prevalence of admissions for males is also in agreement with data 
Table 6 - The hospitalization coefficients (per 1,000 children) for the major hospitalization causes in children between five and nine years old - São Paulo and Brazil, 2002 to 2006

\begin{tabular}{lccccccc}
\hline Causes & Place & 2002 & 2003 & 2004 & 2005 & 2006 & Variation \\
\hline \multirow{2}{*}{ Respiratory } & São Paulo & 4.47 & 5.25 & 5.81 & 6.86 & 6.02 & $+34.6 \%$ \\
& Brazil & 7.81 & 7.27 & 7.10 & 7.20 & 6.58 & $-15.7 \%$ \\
\hline \multirow{2}{*}{ Surgical } & São Paulo & 2.71 & 3.73 & 3.89 & 4.09 & 3.89 & $+43.5 \%$ \\
& Brazil & 2.28 & 2.58 & 2.73 & 2.79 & 2.57 & $+12.7 \%$ \\
\hline \multirow{2}{*}{ Secondary to external } & São Paulo & 1.69 & 2.04 & 2.11 & 2.34 & 2.06 & $+21.9 \%$ \\
causes lesions & Brazil & 2.17 & 2.32 & 2.35 & 2.44 & 2.14 & $-1.4 \%$ \\
\hline \multirow{2}{*}{ Nervous system diseases } & São Paulo & 0.56 & 0.66 & 0.84 & 1.19 & 1.28 & $+128 \%$ \\
& Brazil & 0.09 & 0.10 & 0.11 & 0.14 & 0.13 & $+44 \%$ \\
\hline
\end{tabular}

in the literature that describe male gender as a risk factor associated with the hospitalization of children.,11

The first important result is the fact that the CI increased $11 \%$ in the city of São Paulo, while it decreased $14 \%$ in Brazil, over the five years studied. It is important to point out that the changes in São Paulo and Brazil show trends observed during the five years studied (Figure 2). According to LEBRAO (1999), ${ }^{12}$ analyzing decisive reasons for changes in the frequency of diseases is a complex task because of the numerous factors that can be involved. For that discussion, the behavioral model of Andersen (ANDERSEN, 1995) ${ }^{13}$ for the use of health services was chosen as a theoretical reference. According to this author, the use of health services depends on three factors: individual's predisposition (predisposing factors),-enabling factors-which promotes or impedes this use, and the need of health. Included in the predisposing factors are demographic characteristics such as age and gender, social structure and cultural factors. Enabling factors encompass the services offered at the location, along with beds, equipment and health professionals and the idea that an individual must have the means and knowledge to reach health services. Finally, the need for health that can be self-evaluated, noticed by the individual or appraised by the health professional.

The predisposing factors (demographic, social and cultural characteristics) can explain the differences observed between the CIs in the city of São Paulo and Brazil. However, they do not explain the increase in the CI in the city because the appraised age group, children from zero to nine years of age, was the same during the five years studied, and thus, we cannot consider changes in demographic characteristics. In addition, the study period of five years is very short for significant cultural changes to have occurred. The changes observed between 2002 and 2006 were related to improved social conditions and therefore, could not be considered determinants of the increasing hospitalizations in the city of São Paulo. Compared with the socioeconomic indicators of the Interagencial Network of Information for Health (RIPSA) which is part of the Indicators and Basic Data for Brazil 2007 (IDB-2007) ${ }^{14}$ the illiteracy rate decreased, the time spent in school increased, and the GIP per capita increased, in the state of São Paulo and Brazil. This information indicates a decrease of inequalities, a decrease in the unemployment rate and a slight increase in the proportion of poor people.

Enabling factors, such as those factors that impede or facilitate the use of health services, include the availability of services, the distance to those services and the knowledge of how to use those services. These factors suffer directly and indirectly from the health policies adopted. Therefore, considering the historical time of the study, during the first years of the SUS in the city of São Paulo at a time when many changes occurred in the health system and policies, the enabling factors are likely the main influences on the increases in the city's hospitalization coefficients. ANDERSEN (1995) ${ }^{13}$ had already stated that enabling factors are the most varied and, therefore, strongly associated with alterations observed in the use of hospital-related services.

In the present study, the increased CIs observed in São Paulo could not be correlated to an increase of the number of pediatric beds of SUS. According to data from the National Register of Institutions of Health ${ }^{15}$ (CNES - local acronym), in 2002, there were 1.15 beds for every 1,000 children from 0 to 14 years of age; in 2006 , that number fell to 0.59 . In Brazil, there was also a decrease in the number of pediatric beds of SUS, from 1.51 to 1.08 beds for every 1,000 children between 0 to 14 years of age. The present study only corresponds to hospitalizations accomplished by the SUS, and the inclusion of admissions covered by health insurances would probably alter the observed results, especially considering the factors involved in these hospitalizations and the varied population characteristics of this group and those of the SUS.

The offer of basic attention is one factor that influences 
hospitalization rates. CASANOVA and STARFIELD $(1995)^{16}$, who compared Spain and the United States with regard to children's hospitalizations and access to primary care, concluded that hospitalizations can be reduced with greater access to quality primary attention. According to data of DATASUS, in Brazil, the evolution of admissions and external (out-patient) attendance for all age groups during in the period from 2000 to 2006,show that there was a reduction of hospitalizations by $5.2 \%$ and an increase of crowding in out-patient areas by $49.9 \%$. Both vaccine coverage contained in the IDB-2007 and external outpatient activity increased during the studied period in both São Paulo and Brazil. One possible explanation for the paradoxical increase in hospitalizations observed in the city is that, the studied period was the beginning of the primary attention expansion. Additionally, SUS was initiated, and the Family Health Program (PSF) coverage was increased, which could have raised the demand for the hospital due to facilitate access and it was served as an entrance door to the patients who had been repressed by the health system, as described by OLIVEIRA et al (2004) $)^{17} \cdot{ }^{17}$ Comparing the number of families registered in the PSF in December 2001 and December 2006, 48.8\% more families were registered in Brazil, and 369.8\% more families were registered in the city of São Paulo, according to data of DATASUS. This great expansion of PSF in the city may have facilitated the entrance in the health system, increasing CIs. There are still only a few reports in the literature regarding the impact of PSF on infantile morbidity. In relation to the infant mortality rate, however, the effect is severe. MACINKO et al (2006) ${ }^{18}$ found that a $10 \%$ increase in coverage by the PSF facilitated a $4.5 \%$ decrease in infant mortality. SERRA $(2005)^{19}$ found a beneficial impact of PSF over infant mortality even in the most economically developed areas, such as the state of São Paulo. Another aspect related to the expansion of the primary attention refers to the quality of the rendered service. The percentage of hospitalizations for ambulatory care sensitive conditions was quite frequent. In other words, diseases that should have a reduced risk of hospitalization if opportunely diagnosed and properly treated were still being treated in a hospital. ${ }^{20}$ This type of statistic can be used to evaluate the access and quality of primary attention and the impact of new health programs. ${ }^{16+6}$. Among the ten main causes of hospitalization for children from zero to nine years of age, four are conditions that are sensitive to ambulatory care: pneumonia, asthma, diarrhea and acute bronchitis. SILVA et al (1999) ${ }^{4}$ also verified, in São Luís, a high percentage of hospital admissions for conditions sensitive to external attention, leading to the conclusion that, despite expanded access to primary care the external (out-patient) care is still of low resolution, mainly among the poorest people.
The third factor contained in the theoretical model of Andersen is the need for health, which refers to the conditions of health that justify the need to use health services. It includes morbidity, and it could possibly influence the variations in CI, which will be discussed when the causes of hospitalization are analyzed.

Diseases of the respiratory system, particularly pneumonia, were the main causes of hospitalization in children from zero to nine years old in both the municipal district and Brazil, which corresponds to $32 \%$ and $38 \%$ of the admissions, respectively. These percentages were also found in several other studies. ${ }^{3,21,22}$ Individual factors, such as immunological immaturity and the anatomical characteristics of the respiratory tree, along with life habits that predispose to exposure to infectious and irritating agents affecting the respiratory tract, explain the vulnerability of the pediatric age group to respiratory diseases. ${ }^{23,24}$ In addition to standing out as the most frequent condition, this study observed CIs for those causes increased in the city and decreased in Brazil, for the three appraised age groups. The increase in hospitalizations and the decrease in the proportion of deaths, verified in IDB-2007, may reflect an increase in the prevalence of respiratory diseases, in the context of greater access to health services. In fact, BENÍCIO et al $(2000)^{25}$ already described an increase in the prevalence of respiratory diseases in home inquiries performed in 1984/85 and 1995/1996 in the city of São Paulo. Those authors attributed the higher prevalence of respiratory diseases to an increase in the frequency of infantile nurseries and, possibly, to worsening air quality. Later, other authors found an association between climate conditions and the hospitalization rate for respiratory diseases. ${ }^{26,27}$ In São Paulo, the total pollutants in the air are nearly twice as much as in other big cities, such as Belo Horizonte, Curitiba, Porto Alegre and Recife. Therefore, the climate conditions and the increase of the prevalence of respiratory diseases provide explanations for the increase in hospitalization coefficients observed in the city. We must also consider that the lack of specific programs for those conditions can influence these findings. Regarding asthma, for instance, LASMAR et al $(2002)^{28}$ emphasize that, although there is a national and international consensus for the treatment of asthma, such knowledge has not been incorporated into clinical practice, and the non-existence of external, regular follow-up shifts the demand toward hospitals and emergency services.

In the city of São Paulo, diseases that originated in the perinatal period corresponded to $16 \%$ of the appraised hospitalizations and were the second cause of hospital admissions. The study of LENZ et al (2008) ${ }^{2+},{ }^{21}$ performed in Porto Alegre, indicates that $14 \%$ of the hospitalizations were related to perinatal causes. This result is comparable to that 
found in our study, which is may be due to the fact that the two areas have similar socioeconomic characteristics. Therefore, as seen for the respiratory diseases, an increase in hospitalizations related to perinatal causes was observed in the city.

The neonatal mortality rate has not undergone the same decline as the infant mortality rate. In response to this preoccupying concern, in 2004 the Ministry of Health presented the National Pact for the Reduction of the Maternal and Neonatal Mortality, which recommends the establishment of the Committees of Prevention of the Infantile and Fetal Deaths. These committees should identify risk factors involved and propose measures to improve the quality of the rendered attendance, with the ultimate objective being a reduction in infantile and fetal deaths. ${ }^{29}$ In 2002, the city hall of São Paulo implemented Projeto Nascer Bem (Being Born Well Project), with the objectives of reducing maternal and perinatal mortality and adopting measures to promote appropriate prenatal follow-up, safe delivery and care to the puerperal and the newborn.

In terms of prenatal coverage indicators, the National Research of Demography and Health of the Child and of the Woman (PNDS- local acronym) of $2006^{30}$ revealed that the number of mothers who did not attend any prenatal follow-up decreased from 14\% in 1996 to $1 \%$ in 2006. In fact, according to data from the IDB- $2007^{14}$, the percentage of pregnant women in Brazil who attended seven or more prenatal consultations increased from $47.39 \%$ in 2001 to $53.63 \%$ in 2005. In São Paulo, that increase was even more significant, increasing from $57.91 \%$ to $71.39 \%$. In relation to the indicators of results, both the mortality rate for diseases that originated in the perinatal period and nor the proportion of live newborns with low birth weight didn't presented significant improvements. The continued high mortality rates, mainly in the early neonatal period; the high prevalence of low weight birth children, a condition considered to be the most direct indicator of health in the perinatal period; ${ }^{31}$ and the increase observed in hospitalizations for those causes may demonstrate that the greater access to prenatal health care was not necessarily of the best quality. This issue is perhaps explained by the period of time examined in the study, the years including the beginning of SUS in the city of São Paulo. Therefore, it was a time of restructuring health policies and renewing and recruiting of professionals.

In São Paulo, the characteristics of morbidity are similar to those found in developed countries: predominance of respiratory and perinatal causes, along with reduced importance of infect-contagious diseases. On the other hand, research performed in other areas of the country describe diarrhea as the second cause of hospitalization in children. ${ }^{4,22}$ The importance of diarrhea as an admission cause in the rest of Brazil could also be verified in the present study because in chapter I of the CID-10, infectious and parasitic diseases including diarrhea and gastroenteritis of infectious origin were the second leading cause of hospitalizations (22\%) in Brazil.

In the city of São Paulo, those causes were responsible for a very lower percentage of hospitalizations, $8 \%$, which comes in fourth for children from zero to nine years of age. The attention surrounding diarrhea stems from the increasing CIs in the city of São Paulo, during the studied period. In Brazil, those hospitalizations tended to decrease among children younger than 1 year old, while in São Paulo, those hospitalizations were 1.5 times more frequent. That finding was also observed for children between one and four years of age, where double the number of admissions were verified for that cause in 2006 compared with 2002. One possible reason for that increase would be the change in the etiological profile of diarrheas, with fewer bacterial causes, which are more sensitive to basic sanitation, and more viral diarrheas. This change in the etiological profile of diarrheas had already been observed by SOUZA et al $(2002)^{32},{ }^{32}$ who described a relative increase of the prevalence of the rotavirus. Therefore, in spite of São Paulo being a privileged place in terms of water supply (greater than 97\%) and sewer system (around $90 \%$ ), it presents unfavorable conditions with respect to viral infections, as was already described for the respiratory diseases. We must mention that the vaccine against rotavirus became part of the basic vaccination calendar in 2006, which is the last year of the period analyzed in the present study. Even in these cases, only children in the first semester of life took advantage of the vaccine. Another possible reason for the increase in CIs would be the inadequacy of the treatment for diarrhea. BITTENCOURT et al (2002) $)^{8}$ verified, in 1996 in Rio de Janeiro, an excess of admissions for diarrhea in SUS hospitals, concluding that there are unnecessary hospitalizations that were motivated by errors in the rendered attendance. According to data from PNDS-2006, ${ }^{30}$ the states of the south and southeast use oral rehydration therapy (TRO) less frequently; fewer than $50 \%$ of the children received that kind of treatment. The reduction in the use of TRO may be one of reason for the increased hospitalizations for diarrhea observed in the district of São Paulo.

The discussion of possible factors involved in the variations observed in the hospitalization rates was presented following the theoretical model of Andersen. However, it is critical to consider that these factors interact amongst themselves in a complex way. Besides, many context factors that are not measurable may be involved in the network of multicausality and, consequently, could interfere with the CIs presented in this study. 


\section{CONCLUSION}

In the last few decades, an important reduction has been observed in infant mortality, with changes to the profile of the mortality causes. However, the analysis of hospitalizations in the city of São Paulo showed an increased number of hospital admissions. A curious fact is that, in that same study period, there was a significant increase of out-patient procedures. Although one cannot deny the importance of hospitalization in cases when the patient needs more specific and intense care, most of the medical practice is performed through ambulatory services.

One conclusion is that the increase of out-patient care was not accompanied by a significant improvement in the quality of service, mainly in primary care. This idea is supported in the present study, where many patients were hospitalized for ambulatory care sensitive conditions. It is possible, therefore, to reduce hospitalizations by investing in external attention and mainly in primary care.

The current study presented information and hypotheses to explain the profile of hospitalizations in the examined population. We suggest that additional studies with other designs are needed to verify the specificity of the factor conditioning the admissions. It is important to perform a detailed study that determines the causes of hospitalization in order to aid the development of public policies that promote interventions with the goal of reducing the number of hospitalizations in the city of São Paulo and Brazil.

\section{REFERENCES}

1. Goldbaum M. Epidemiologia e serviços de saúde. Cad Saúde Pública, Rio de Janeiro 1996; 12(supl. 2):95-8.

2. Prata PR. A transição epidemiológica no Brasil. Cad Saúde Pública, Rio de Janeiro. 1992;8:168-75.

3. Caetano JRM, Bordin IAS, Puccini RF, Peres CA. Fatores associados á internação hospitalar de crianças menores de cinco anos, São Paulo, SP. Rev Saúde Pública. 2002;36:285-91.

4. Silva AAM, Gomes UA, Tonial SR, Silva RA. Fatores de risco para hospitalização de crianças de 1 a 4 anos em São Luís, Maranhão, Brasil. Cad Saúde Pública, Rio de Janeiro. 1999;15:749-57.

5. Carvalho DM. Grandes sistemas nacionais de informação em saúde: revisão e discussão da situação atual. Inf Epidemiol SUS. 1997;5:7-46.

6. Pereira MG. Morbidade. In: Pereira MG. Epidemiologia: teoria e prática. Rio de Janeiro: Guanabara-Koogan;1995,76-104.

7. Campos GJV, Reis Filho AS, Silva AAM, Novochadio MAS, Silva RA, Galvão CES. Morbimortalidade infantil por diarréia aguda em área metropolitana da região Nordeste do Brasil, 1986-1989. Rev Saúde Pública. 1995;29:132-9.

8. Bittencourt SA, Camacho LAB, Leal MC. O Sistema de Informação Hospitalar e sua aplicação na saúde coletiva. Cad Saúde Pública. Rio de Janeiro. 2006;22:19-30.

9. Mendes ACG, Albuquerque PC, Lessa FD, Maciel Filho R, Farias SF, Montenegro TO. Sistema de informações hospitalares - fonte complementar na vigilância e monitoramento das doenças de transmissão vetorial. Inf Epidemiol SUS. 2000;9:125-36.

10. Figueiredo GLA, Mello DF. Atenção à saúde da criança no Brasil: aspectos da vulnerabilidade programática e dos direitos humanos. Rev. Latino-am Enfermagem. 2007;15:1171-6.

11. Castro MSM, Travassos C, Carvalho MS. Fatores associados às internações hospitalares no Brasil. Ciência \& Saúde Coletiva. 2002;7:795-811.

12. Lebrão ML. Determinantes da morbidade hospitalar em região do Estado de São Paulo (Brasil). Rev Saúde Pública. 1999; 33:55-63.
13. Andersen RM. Revisiting the behavioral model and Access to medical care: does it matter? J Health Social Behav. 1995;36:1-10.

14. IDB - Indicadores e Dados Básicos - Brasil 2007. (acessado em 05/03/2009). Disponível: http:// tabnet.datasus.gov.br/cgi/idb2007/ matriz.htm

15. Cadastro Nacional de estabelecimentos de Saúde (CNES). (acessado em 20/03/2009). Disponível: http://www.cnes.datasus.gov.br

16. Casanova C, Starfield B. Hospitalizations of children and Access to primary care: a cross-national comparison. Int J Health Serv. 1995;25:283-94.

17. Oliveira EXG, Travassos C, Carvalho MS. Acesso à internação hospitalar nos municípios brasileiros em 2000: territórios do Sistema Único de Saúde. Cad Saúde Pública, Rio de Janeiro 2004; 20(sup 2):S298-S309.

18. Macinko J, Guanais FC, Souza MFM. Evaluation ot the impact of the Family Health Program on infant mortality in Brazil, 1990-2002 J. Epidemiol Community Health. 2006;60:13-9.

19. Serra RAM. Uma avaliação do impacto do programa da família sobre a saúde infantil no Estado de São Paulo. Trabalho submetido ao Prêmio Economia da Saúde, IPEA. Brasília/DF; 2005.

20. Parchman ML, Culler S. Primary care physicians and avoidable hospitalizations. J Fam Pract. 1994;39:123-8.

21. Lenz MLM, Pires NV, Stein AT, Flores R. Hospitalizações entre crianças e adolescentes no território de abrangência de um serviço de atenção primária. Revista Brasileira Saúde da Família. 2008;18:9-14.

22. Cesar JA, Horta BL, Gomes G, Shehadeh I, Chitolina J, Rangel L, et al. Utilização de serviços de saúde por menores de cinco anos no extremo Sul do Brasil. Cad. Saúde Pública, Rio de Janeiro. 2002;18:299-305.

23. Bresolin AMB, Kobinger MEBA, Sucupira ACSL. Afecções respiratórias. In: Bresolin AMB, Sucupira ACSL. Caderno temático da criança, Prefeitura do município de São Paulo. São Paulo, 2003.

24. Benguigui, Y. Acute respiratory control in the context of the IMCI strategy in the America. Rev bras saúde matern infant, Recife. 2003;3:2536. 
25. Benicio MHD'A, Cardoso MRA, Gouveia NC, Monteiro CA. Tendência secular da doença respiratória na infância na cidade de São Paulo (19841996). Rev. Saúde Pública. 2000;34(6 supl):91-101.

26. Gouveia N, Freitas CV, Martins LC, Marcílio IO. Hospitalizações por causas respiratórias e cardiovasculares associadas à contaminação atmosférica no município de São Paulo. Cad. Saúde Pública, Rio de Janeiro. 2006;22:2669-77.

27. Botelho C, Correia AL, Silva AMC, Macedo AG, Silva COS. Fatores ambientais e hospitalizações em crianças menores de 5 anos com infecção respiratória aguda. Cad. Saúde Pública, Rio de Janeiro. 2003;19:1771-80.

28. Lasmar LMLBF, Goulart E, Sakurai E, Camargos P. Fatores de risco para hospitalização de crianças e adolescentes asmáticos. Rev Saúde Pública. 2002;36:409-19.
29. Brasil. Ministério da Saúde. Manual dos comitês de prevenção do óbito infantil e fetal. Série A. Normas e manuais técnicos. Brasília/DF. Ministério da Saúde 2004.

30. Brasil. Ministério da Saúde. PNDS 2006: Pesquisa Nacional de Demografia e Saúde da Criança e da Mulher. Relatório. Brasília/DF: Ministério da Saúde 2008.

31. Tanaka ACd'A, Siqueira AAF, Bafile PN. Situação de saúde materna e perinatal no estado de São Paulo, Brasil. Rev Saúde Pública. 1989;23:6775.

32. Souza EC, Martinez MB, Taddei CR, Mukai L, Gilio A, Racz ML, et al. Perfil etiológico das diarréias agudas de crianças atendidas em São Paulo. J Pediatr (Rio J). 2002;77:31-8. 